\title{
Identification of metallo- $\beta$-lactamases and AmpC production among Escherichia coli strains isolated from hemodialysis patients with urinary tract infection
}

\author{
Aghil Bahramian ${ }^{1} \cdot$ Saeed Khoshnood ${ }^{2} \cdot$ Nader Hashemi $^{3} \cdot$ Melika Moradi $^{4} \cdot$ Mohammadmahdi Karimi-Yazdi $^{5}$. \\ Nahid Jalallou' ${ }^{1} \cdot$ Morteza Saki ${ }^{4}[$
}

Received: 22 August 2021 / Accepted: 5 October 2021 / Published online: 17 October 2021

(c) The Author(s), under exclusive licence to Springer Nature B.V. 2021

\begin{abstract}
Background This study aimed to identify metallo- $\beta$-lactamases (MBLs) and AmpC $\beta$-lactamases-producing Escherichia coli isolates obtained from hemodialysis (HD) patients with urinary tract infections (UTI).

Methods and results A total of $257 \mathrm{HD}$ patients with UTI were included in this study, from which 47 E. coli isolates were collected. Antibiotic susceptibility was tested by disc diffusion method. MBLs and AmpC production were phenotypically detected by imipenem-ethylenediaminetetracetate and cefoxitin/boronic acid assays, respectively. The presence of MBLs and AmpC genes was examined by polymerase chain reaction (PCR). Fosfomycin and ampicillin were the most and the least effective antibiotics against $E$. coli isolates, respectively. Moreover, 61.7\% (29/47) of E. coli isolates were multidrug-resistant with seven different antibiotypes. Antibiotype V (AMP-CIP-IMP-MEM-CPD-CRO-CTX-GEN-LEV-SXT-TOB) was the most prevalent profile. Besides, 24 (51.1\%) isolates were simultaneously resistant to imipenem and meropenem. Phenotypic assay showed MBL production in 16 (66.7\%) of the 24 carbapenem-resistant $E$. coli isolates. The distribution of MBL genes in carbapenem-resistant $E$. coli was as follows: $b l a_{\mathrm{IMP}} 18(72 \%), b l a_{\mathrm{VIM}} 7(28 \%)$, and $b l a_{\mathrm{NDM}} 1$ (4\%). AmpC was detected in 61.7\% (29/47) of the isolates using the phenotypic method. The presence of AmpC genes was confirmed by PCR in only 26 of 29 (86.7\%) AmpC producers. The frequencies of $b l a_{\mathrm{DHA}-1}, b l a_{\mathrm{ACC}}$, and $b l a_{\mathrm{CMY}-2}$ were 6 (20.7\%), 11 (37.9\%), and 21 (72.4\%), respectively.
\end{abstract}

Conclusions The emergence of MBL and AmpC coproducing E. coli isolates calls for an urgent surveillance program for timely diagnosis and screening of these genes in our healthcare systems.

Keywords AmpC $\cdot$ Escherichia coli $\cdot$ Hemodialysis patients $\cdot$ Metallo- $\beta$-lactamases $\cdot$ Urinary tract infections

Nahid Jalallou

nahidjalallou@yahoo.com

$\triangle$ Morteza Saki

mortezasaki1981@gmail.com

1 Department of Medical Laboratory Sciences, AJA University of Medical Sciences, Tehran, Iran

2 Clinical Microbiology Research Center, Ilam University of Medical Sciences, Ilam, Iran

3 Department of Biotechnology, School of Advanced Technologies in Medicine, Shahid Beheshti University of Medical Sciences, Tehran, Iran

4 Department of Microbiology, Faculty of Medicine, Ahvaz Jundishapur University of Medical Sciences, Ahvaz, Iran

5 Faculty of Paramedical Sciences, Mazandaran University of Medical Sciences, Sari, Iran

\section{Introduction}

Dialysis is a procedure to remove excess fluids and waste products from the human body. There are two different methods of dialysis: peritoneal dialysis and hemodialysis (HD). The second method uses a machine located outside the body to remove blood and pump it into a dialyzer [1]. HD patients are at high risk for various infections, not only due to the invasiveness of this method, but also because of the immunosuppression caused by the inflammation and uremia [2]. In HD patients with chronic renal disease, infection is the leading cause of death. These patients are at risk of urinary tract infections (UTIs) which can lead to serious complications. Because of the problems in collecting urine samples from anuric or oliguric HD patients, UTIs are initially difficult to diagnose. Previous evidence suggests that multidrug-resistant bacterial 
pathogens of UTIs are more common in HD patients compared with those with normal renal function [3]. Despite extensive studies on UTIs in many countries, little is known about hemodialysis patients.

Infections such as UTIs, cause high economic costs and morbidity rates, making them one of the most significant diseases in hospitals and communities. In Asia, UTIs are the main causes of mortality and morbidity. According to diagnostic and clinical reports, approximately 150 million people become infected with UTI each year worldwide [4,5]. The prevalence of UTIs is mainly influenced by a variety of factors including gender, age, urological instruments, impaired immunity, indwelling urinary catheters, and underlying diseases such as diabetes mellitus [6]. Escherichia coli, Klebsiella pneumoniae, Staphylococcus aureus, Enterococcus faecalis, and Proteus mirabilis are the commonest bacteria causing UTIs. Community-acquired UTI is most commonly caused by $E$. coli bacteria, which are abundant in the gastrointestinal microflora of humans [7, 8].

Treatment of infections has been complicated by the emergence of multidrug-resistant (MDR) strains of $E$. coli. Betalactam antibiotics are prescribed drugs for UTI treatment. These agents are a class of extended-spectrum antibiotics and include all antibiotics that have a $\beta$-lactam ring in their structure $[9,10]$. The worldwide distribution of E. coli harboring metallo- $\beta$-lactamases (MBLs) and AmpC $\beta$-lactamases $(\mathrm{AmpC})$ is a serious threat, and due to MBL production, carbapenem resistance is progressively spreading among clinical isolates of $E$. coli [11]. Varied types of MBL genes have been identified around the world. The $b l a_{\mathrm{NDM}}, b l a_{\mathrm{VIM}}$, and $b l a_{\mathrm{IMP}}$ are among the most common MBLs [12].

The increasing emergence of AmpC ( $p A m p C) \beta$-lactamases mediated by plasmids is also of growing concern. Six families of $p A m p C \beta$-lactamases have been defined by Pérez-Pérez and Hanson as EBC, MOX, FOX, CIT, DHA, and ACC. Among E. coli strains, the CMY-2 type is the most commonly known $p A m p C$. In recent decades, the frequency of AmpC-producing E. coli strains, which are mostly MDR, has increased significantly. Therefore, the detection of AmpC-positive strains is of utmost importance for appropriate treatment [13].

Considering the importance of these issues and knowing that studies on the prevalence of $\beta$-lactamase genes in E. coli strains isolated from HD patients with UTIs from all over the world, and especially from Iran are very rare, this study aimed to identify the MBLs and AmpC $\beta$-lactamases-producing $E$. coli isolates in HD patients with UTIs.

\section{Methods}

\section{Study design and specimen collection}

This descriptive cross-sectional study was conducted from October 2019 to July 2020. Written informed consent was obtained from all patients who participated in this study before the start of the work. A total of 257 HD patients with clinical suspicion of UTI (fever, chills, burning sensation during urination, cloudy urine, frequent and low urine output, unpleasant odor of urine) admitted to Army hospitals in Tehran city, were included in this study. The Army hospitals are located in Tehran, the capital of the country of Iran. These hospitals are for general referral and have all specialized and advanced medical departments. All patients with suspected UTI symptoms had their urine samples collected by clean-catch midstream protocol. A urine specimen was deemed positive for UTI if it contains a single microorganism with a count of $\geq 10^{5} \mathrm{CFU} / \mathrm{ml}$. E. coli isolates were identified by phenotypic and biochemical tests including Gram staining, lactose fermentation on MacConkey agar, triple sugar iron agar reaction, indole production, motility test, and Simmons' citrate test [14]. All culture media used in this study, were prepared and purchased from Merck Co, Germany.

\section{Antibiotic susceptibility testing (AST)}

AST was conducted using disc diffusion method, according to the recommendations of Clinical and Laboratory Standards Institute (CLSI) [15]. The AST was performed with the following antibiotic discs: imipenem (IMP, $10 \mu \mathrm{g}$ ), meropenem (MEM, $10 \mu \mathrm{g}$ ), amikacin (AMK, $30 \mu \mathrm{g}$ ), gentamicin (GEN, $10 \mu \mathrm{g}$ ), tobramycin (TOB, $10 \mu \mathrm{g}$ ), ampicillin (AMP, $10 \mu \mathrm{g}$ ), cotrimoxazole (SXT, $25 \mu \mathrm{g}$ ), fosfomycin (FOS, $10 \mu \mathrm{g}$ ), piperacillin-tazobactam (PTZ, 100/10 $\mu \mathrm{g}$ ), ceftriaxone $(\mathrm{CRO}, 10 \mu \mathrm{g})$, ceftazidime (CAZ, $30 \mu \mathrm{g})$, cefpodoxime (CPD, $10 \mu \mathrm{g}$ ), cefotaxime (CXT, $30 \mu \mathrm{g}$ ), nitrofurantoin (NF, $300 \mu \mathrm{g}$ ), ciprofloxacin (CIP, $10 \mu \mathrm{g}$ ), and levofloxacin (LEV, $10 \mu \mathrm{g}$ ) (Mast, UK). E. coli ATCC 25922 was used as a control strain for the susceptibility tests. Isolates resistant to at least three classes of antibiotics were considered as MDR isolates.

\section{Phenotypic detection of MBLs}

The presence of MBLs was screened by the combined imipenem-ethylenediaminetetracetate (IMP-EDTA) disc test. Briefly, isolates to be tested were inoculated on a Mueller Hinton Agar (Merck Co, Germany) plate using lawn culture method. One disc of IMP $(10 \mu \mathrm{g})$ alone and another 
disc in combination with EDTA $(750 \mu \mathrm{g} / \mathrm{ml})$ were applied $20 \mathrm{~mm}$ apart and incubated for $18-24 \mathrm{~h}$ at $37^{\circ} \mathrm{C}$. Strains were confirmed as MBL producers once an increase of $\geq 7$ $\mathrm{mm}$ in the inhibition zone of IMP-EDTA combination disc was observed compared to the IMP disc alone [16].

\section{Phenotypic detection of AmpC}

The cefoxitin (FOX) disc $(30 \mu \mathrm{g}) /$ boronic acid was used to screen AmpC-producing isolates as previously described [17]. Isolates with the inhibition zones of $<18 \mathrm{~mm}$ in diameter against FOX discs were considered potentially positive for AmpC screening and were subjected to further testing, using FOX disc alone and in combination with boronic acid (Sigma, USA). The presence of a 5-mm or larger increase in the inhibition zone diameter of the FOX disc in combination with boronic acid compared to the FOX alone, was considered as positive AmpC production.

\section{Molecular detection of MBLs and AmpC genes}

The presence of AmpC genes ( $b l a_{\mathrm{CMY}-2}$, bla $a_{\mathrm{DHA}-1}$, and $\left.b l a_{\mathrm{ACC}}\right)[18]$ and MBLs genes $\left(b l a_{\mathrm{IMP}}, b l a_{\mathrm{VIM}}\right.$, and $\left.b l a_{\mathrm{NDM}}\right)$ [19] was detected by polymerase chain reaction (PCR). Genomic DNA extraction was performed using the boiling method [20]. The PCR was performed in a final volume of $25 \mu \mathrm{l}$ consisting of DNA template ( $50 \mathrm{ng}$ ), dNTPs $(100 \mu \mathrm{M})$, Taq buffer $(5 \times)$, Taq DNA polymerase (1 U; Cinnagen, Iran), and forward and reverse primers (25 $\mathrm{pM}$ each). The PCR mixtures were subjected to thermal cycling. PCR reactions included 30 amplification cycles in a Mastercycler (Eppendorf, Germany) under the following conditions: denaturation at $95{ }^{\circ} \mathrm{C} / 5 \mathrm{~min}$, annealing at $55^{\circ} \mathrm{C} / 30 \mathrm{~s}$, and extension at $72{ }^{\circ} \mathrm{C} / 45 \mathrm{~s}$, with a final extension at $72{ }^{\circ} \mathrm{C} / 6 \mathrm{~min}$. Amplified products were visualized using electrophoresis on a $1 \%$ agarose gel stained with safe stain (Sinaclon, Iran), in a Tris-Borate-EDTA buffer (Promega, USA). Water was used as a negative control in the study, and the positive controls were K.pneumoniae ATCC 700603, P.aeruginosa ATCC 27853, P.aeruginosa ST 147, K.pneumoniae KP696465, E.coli KX 342010 and E.coli KX342011.

\section{Statistical analysis}

Data were entered and statistically analyzed using Microsoft Excel 2019 (Microsoft Corporation, USA) and the Statistical Package for the Social Sciences (SPSS) software version 22 (IBM SPSS Statistics, USA) [21]. The results were presented as descriptive statistics in the form of relative frequency.

\section{Results}

\section{Bacterial isolates and antibiotic resistance}

In this study, a total of $47 \mathrm{E}$. coli isolates were obtained from urine samples of HD patients, with an overall prevalence of $18.3 \%$ (47/257). The isolates were obtained from $21(44.7 \%)$ males and $26(55.3 \%)$ females (female/male ratio $=1.23$ ), respectively. The mean age of the patients was $(31 \pm 1)$ years, and ranged from 2 to 65 years. The $E$. coli isolates showed the highest susceptibility $(87.2 \%)$ and esistance (100\%) to FOS and AMP antibiotics, respectively. PTZ and NF were the second and third most effective antibiotics, respectively. More than $70 \%$ of the isolates were resistant against third-generation cephalosporin (TGC) antibiotics. As well, 24 (51.1\%) isolates were simultaneously resistant to IMP and MEM. The susceptibility rate results for all antibiotics tested are shown in Table 1. The results of AST showed that $61.7 \%$ (29/47) of $E$. coli isolates were MDR with seven different antibiotypes (Table 2). Antibiotype V (AMP-CIPIMP-MEM-CPD-CRO-CTX-GEN-LEV-SXT-TOB) was the most prevalent profile (31.0\%).

\section{Detection of MBLs and AmpC genes}

The results of the IMP-EDTA combined disc test confirmed the MBL production in 16 (66.7\%) out of 24 carbapenem-resistant E. coli isolates. PCR results showed that all 24 carbapenem-resistant $E$. coli isolates had at least one MBL gene. The distribution of MBL genes among

Table 1 The results of antibiotic susceptibility testing

\begin{tabular}{llll}
\hline Antibiotic & \multicolumn{2}{l}{ Total Escherichia coli, N (\%) } \\
\cline { 2 - 4 } & Sensitive & Intermediate & Resistant \\
\hline Gentamicin & $12(25.5)$ & $8(17.0)$ & $27(57.4)$ \\
Amikacin & $28(59.6)$ & $10(21.3)$ & $9(19.1)$ \\
Levofloxacin & $27(57.4)$ & $2(4.3)$ & $18(38.3)$ \\
Ciprofloxacin & $18(38.3)$ & - & $29(61.7)$ \\
Tobramycin & $14(29.8)$ & $5(10.6)$ & $28(59.6)$ \\
Fosfomycin & $41(87.2)$ & - & $6(12.8)$ \\
Cefpodoxime & $7(14.9)$ & $4(8.5)$ & $36(76.6)$ \\
Cefotaxime & $9(19.1)$ & $4(8.5)$ & $34(72.3)$ \\
Ceftriaxone & $7(14.9)$ & - & $40(85.1)$ \\
Ceftazidime & $4(8.5)$ & $7(14.9)$ & $36(76.6)$ \\
Ampicillin & - & - & $47(100)$ \\
Cotrimoxazole & $9(19.1)$ & - & $38(80.9)$ \\
Meropenem & $23(48.9)$ & - & $24(51.1)$ \\
Imipenem & $19(40.4)$ & $4(8.5)$ & $24(51.1)$ \\
Piperacillin-tazobactam & $38(80.9)$ & - & $9(19.1)$ \\
Nitrofurantoin & $36(76.6)$ & - & $11(23.4)$ \\
\hline
\end{tabular}


Table 2 Different antibiotypes of 29 multidrug-resistant (MDR) E. coli isolates

\begin{tabular}{llc}
\hline MDR profile & Antibiotypes & $\begin{array}{l}\text { Number } \\
\text { of isolates } \\
(\%)\end{array}$ \\
\hline I & CIP-CPD-CRO-CTX-SXT-TOB-NF & $1(3.4)$ \\
II & AMP-CAZ-CIP-PTZ-IMI-MEM-CPD-CRO-CTX-FOS-GEN-SXT-TOB-LEV & $4(13.8)$ \\
III & AMP-CAZ-CIP-PTZ-IMI-MEM-CPD-CRO-CTX-GEN-LEV-SXT-TOB & $5(17.2)$ \\
IV & AMP-AN-CIP-CPD-CRO-CTX-GEN-SXT-TOB-NF & $3(10.3)$ \\
V & AMP-CIP-IMI-MEM-CPD-CRO-CTX-GEN-LEV-SXT-TOB & $9(31.0)$ \\
VI & AMP-AN-CIP-IMI-MEM-CPD-CRO-CTX-GEN-SXT-TOB-NF & $6(20.7)$ \\
VII & CIP-CPD-CRO-CTX-SXT-NF & $1(3.4)$ \\
\hline
\end{tabular}

AMP Ampicillin, AN Amikacin, CAZ Ceftazidime, CIP Ciprofloxacin, CPD Cefpodoxime, CRO Ceftriaxone, CTX Cefotaxime, FOS Fosfomycin, GEN Gentamicin, IMI Imipenem, LEV Levofloxacin, MEM Meropenem, NF Nitrofurantoin, PTZ Piperacillin-tazobactam, SXT Cotrimoxazole, TOB Tobramycin

carbapenem-resistant $E$. coli isolates was as follows: $b l a_{\mathrm{IMP}}$ $18(72 \%)$, bla $a_{\mathrm{VIM}} 7$ (28\%), and bla ${ }_{\mathrm{NDM}} 1$ (4\%). Two isolates showed coexistence of MBL genes. Results from FOX disc/boronic acid detected 61.7\% (29/47) potential AmpC producers. However, the presence of AmpC genes was confirmed by PCR in only 26 of $29(86.7 \%)$ AmpC producers. The frequency rates of the resistance genes $b l a_{\mathrm{DHA}-1}, b l a_{\mathrm{ACC}}$, and $b l a_{\mathrm{CMY}-2}$ among AmpC $\beta$-lactamase-producing strains were $6(20.7 \%), 11(37.9 \%)$, and $21(72.4 \%)$, respectively. Ten isolates showed coexistence of AmpC genes. Overall, the frequencies of $\mathrm{MBL}$ and $\mathrm{AmpC}$ genes were $51.1 \%$ (24/47) and 55.3\% (26/47), respectively. Fifteen (31.91\%) E. coli isolates had no MBL and AmpC genes, and 18 (38.3\%) isolates had both of these genes, simultaneously (Table 3). The electrophoresis image of some MBL and AmpC positive isolates is shown in Fig. 1.

\section{Discussion}

At present, a paucity of epidemiological information is available on E. coli strains causing UTIs, as well as on their antibiotic resistance profiles and resistance mechanisms in HD patients from many countries including Iran. The novelty of this study was to address these issues in a region of Iran. The present study investigated the prevalence and antibiotype patterns of UTI-causing $E$. coli isolates in HD patients against 16 antibiotics.

The results showed an overall prevalence of $18.3 \%$ for UTI-causing $E$. coli isolates in HD patients. This rate was much lower than the rate $(43 \%)$ reported by Sadeghi et al. [22] from Isfahan, Iran, but in kidney transplant patients. In another research in USA, a frequency rate of $29.3 \%$ was reported for $E$. coli isolates in HD patients [23]. The rationale behind these discrepancies is likely the differences in studied population, patient screening programs, and predominant pattern of UTI-inducing pathogens in each region.
According to the results of AST, MEM and IMP were among the relatively least effective antibiotics, with resistance rates of about $50 \%$. These results were in contradiction with previous reports by Critchley et al. [24] from USA, Raeispour et al. [25] from Iran, and Duicu et al. [26] from Romania who showed the efficacy of more than $90 \%$ for these two antibiotics. The emergence of carbapenemresistant Gram-negative bacteria in recent years has posed a new challenge to medical centers, both in Iran and other parts of the world $[27,28]$. This phenomenon may arise from the high prevalence of different carbapenemase genes that can develop resistance to carbapenem antibiotics [28]. Although FOS was the most effective antibiotic, its resistance rate $(12.8 \%)$ was higher than the rate reported in South Korea (6.7\%) [29].

Of the three aminoglycosides studied here, AMK showed the highest efficacy compared to GEN and TOB, supporting previous studies from USA [24] and Gabon [30]. However, a survey by Kushwaha et al. [31] from Nepal showed an opposite result: GEN had higher efficacy against UTI-inducing $E$. coli isolates than AMK and TOB. In this study, more than half of the $E$. coli isolates were resistant to GEN and TOB, which was higher than the report of Naziri et al. [32] from Iran.

This higher resistance rate could be explained by the excessive parenteral administration of these antibiotics in our region. Our study explored a high resistance rate, ranging from 72.3 to $85.1 \%$, against TGC antibiotics, which was in agreement with previous researches conducted by Raeispour et al. [25] and Lee et al. [33], but in contrast to findings achieved from USA [24] and Gabon [30]. The high resistance rates against TGCs is possibly rooted in increasing the spread of extended-spectrum $\beta$-lactamase genes in UTI pathogens in Iran and other countries during recent decades, which were not investigated in the current study [34, 35]. 
Table 3 MBLs and AmpC profiles of all 47 Escherichia coli isolates

\begin{tabular}{|c|c|c|c|c|c|}
\hline Strain ID & Gender & $\begin{array}{l}\text { AmpC } \\
\text { producer }\end{array}$ & $\begin{array}{l}\text { MBL pro- } \\
\text { ducer }\end{array}$ & AmpC genes & MBL genes \\
\hline Ec 1 & M & + & + & $b l a_{\mathrm{DHA}-1}, b l a_{\mathrm{ACC}}$ & $b l a_{\mathrm{IMP}}$ \\
\hline Ec 2 & $\mathrm{~F}$ & + & - & $b l a_{\mathrm{CMY}-2}$ & $b l a_{\mathrm{IMP}}, b l a_{\mathrm{VIM}}$ \\
\hline Ec 3 & M & - & + & - & $b l a_{\mathrm{IMP}}$ \\
\hline Ec 4 & M & + & + & $b l a_{\mathrm{CMY}-2}$ & $b l a_{\mathrm{VIM}}$ \\
\hline Ec 5 & $\mathrm{~F}$ & - & - & - & - \\
\hline Ec 6 & $\mathrm{~F}$ & + & - & $b l a_{\mathrm{DHA}-1}, b l a_{\mathrm{ACC}}, b l a_{\mathrm{CMY}-2}$ & $b l a_{\mathrm{VIM}}$ \\
\hline Ec 7 & M & + & + & $b l a_{\mathrm{CMY}-2}$ & $b l a_{\mathrm{IMP}}$ \\
\hline Ec 8 & $\mathrm{~F}$ & + & - & $b l a_{\mathrm{CMY}-2}$ & $b l a_{\mathrm{VIM}}$ \\
\hline Ec 9 & $\mathrm{~F}$ & - & - & - & - \\
\hline Ec 10 & M & - & + & - & $b l a_{\mathrm{IMP}}$ \\
\hline Ec 11 & $\mathrm{~F}$ & + & + & - & $b l a_{\mathrm{VIM}}$ \\
\hline Ec 12 & $\mathrm{~F}$ & + & - & $b l a_{\mathrm{ACC}}, b l a_{\mathrm{CMY}-2}$ & - \\
\hline Ec 13 & $\mathrm{~F}$ & + & - & $b l a_{\mathrm{CMY}-2}$ & $b l a_{\mathrm{IMP}}$ \\
\hline Ec 14 & M & - & + & - & $b l a_{\mathrm{IMP}}$ \\
\hline Ec 15 & M & - & - & - & - \\
\hline Ec 16 & $\mathrm{~F}$ & + & + & $b l a_{\mathrm{ACC}}, b l a_{\mathrm{CMY}-2}$ & $b l a_{\mathrm{VIM}}$ \\
\hline Ec 17 & $\mathrm{~F}$ & - & - & - & - \\
\hline Ec18 & M & + & + & $b l a_{\mathrm{CMY}-2}$ & $b l a_{\mathrm{IMP}}$ \\
\hline Ec 19 & $\mathrm{~F}$ & - & - & - & - \\
\hline Ec 20 & M & + & + & $b l a_{\mathrm{DHA}-1}, b l a_{\mathrm{ACC}}$ & $b l a_{\mathrm{IMP}}$ \\
\hline Ec 21 & $\mathrm{~F}$ & - & - & - & - \\
\hline Ec 22 & M & + & + & $b l a_{\mathrm{ACC}}$ & $b l a_{\mathrm{VIM}}, b l a_{\mathrm{NDM}}$ \\
\hline Ec 23 & M & + & - & $b l a_{\mathrm{CMY}-2}$ & - \\
\hline Ec 24 & $\mathrm{~F}$ & + & - & $b l a_{\mathrm{CMY}-2}$ & $b l a_{\mathrm{IMP}}$ \\
\hline Ec 25 & M & - & - & - & - \\
\hline Ec 26 & M & + & - & $b l a_{\mathrm{ACC}}$ & - \\
\hline Ec 27 & $\mathrm{~F}$ & + & - & $b l a_{\mathrm{CMY}-2}$ & $b l a_{\mathrm{IMP}}$ \\
\hline Ec 28 & M & - & - & - & - \\
\hline Ec 29 & $\mathrm{~F}$ & + & - & $b l a_{\mathrm{CMY}-2}$ & - \\
\hline Ec 30 & M & - & - & - & - \\
\hline Ec 31 & $\mathrm{~F}$ & + & - & $b l a_{\mathrm{DHA}-1}, b l a_{\mathrm{CMY}-2}$ & $b l a_{\mathrm{IMP}}$ \\
\hline Ec 32 & $\mathrm{~F}$ & + & - & - & - \\
\hline Ec 33 & M & - & - & - & - \\
\hline Ec 34 & M & + & - & $b l a_{\mathrm{CMY}-2}$ & $b l a_{\mathrm{IMP}}$ \\
\hline Ec 35 & $\mathrm{~F}$ & + & - & $b l a_{\mathrm{CMY}-2}$ & - \\
\hline Ec 36 & $\mathrm{~F}$ & + & + & $b l a_{\mathrm{DHA}-1}, b l a_{\mathrm{CMY}-2}$ & $b l a_{\mathrm{IMP}}$ \\
\hline Ec 37 & M & - & + & - & $b l a_{\mathrm{IMP}}$ \\
\hline Ec 38 & $\mathrm{~F}$ & + & - & $b l a_{\mathrm{ACC}}$ & - \\
\hline Ec 39 & $\mathrm{~F}$ & + & - & $b l a_{\mathrm{ACC}}, b l a_{\mathrm{CMY}-2}$ & - \\
\hline Ec 40 & M & - & - & - & - \\
\hline Ec 41 & $\mathrm{~F}$ & + & - & - & - \\
\hline Ec 42 & M & - & + & - & $b l a_{\mathrm{IMP}}$ \\
\hline Ec 43 & $\mathrm{~F}$ & + & + & $b l a_{\mathrm{ACC}}, b l a_{\mathrm{CMY}-2}$ & $b l a_{\mathrm{IMP}}$ \\
\hline Ec 44 & $\mathrm{~F}$ & - & - & - & - \\
\hline Ec 45 & $\mathrm{~F}$ & + & - & $b l a_{\mathrm{CMY}-2}$ & - \\
\hline Ec 46 & M & - & - & - & - \\
\hline Ec 47 & $\mathrm{~F}$ & + & + & $b l a_{\mathrm{DHA}-1}, b l a_{\mathrm{ACC}}, b l a_{\mathrm{CMY}-2}$ & $b l a_{\mathrm{IMP}}$ \\
\hline
\end{tabular}

Ec Escherichia coli, $F$ female, $M$ male, $M B L$ Metallo- $\beta$-lactamase, AmpC AmpC beta-lactamase 


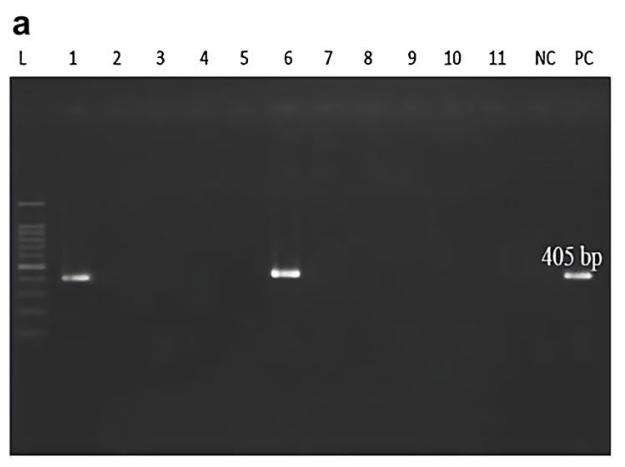

Fig. 1 Agarose gel electrophoresis (1.0\%) of $b l a_{\mathrm{DHA}}$ PCR products. From left to right: L indicates DNA Ladder (100 bp), lanes 1 and 6

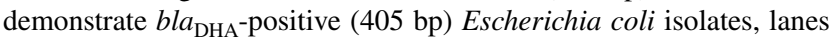
2,3,4,5,7,8,9,10, and 11 indicate bla ${ }_{\mathrm{DHA}}$-negative $E$. coli isolates, $\mathrm{NC}$ indicates negative control, PC indicates positive control of $b l a_{\mathrm{DHA}}$ gene (405 bp) (a). Agarose gel electrophoresis (1.0\%) of bla $a_{\mathrm{IMP}}$ PCR

The resistance rates against CIP and LEV were $61.7 \%$ and $38.3 \%$, respectively. Reports from Iran by Halaji et al. [34] and Raeispour et al. [25] stated the resistance rates of 54.3\% and $34 \%$ for CIP, respectively. These rates were lower than those of the current study. The administration of CIP, as the first-line therapy, against UTI-inducing bacteria might be the reason for this higher resistance rate. Another finding obtained in the present work was the exceptional efficacy of NF with a susceptibility rate of $76.6 \%$.

In line with our result, Lee et al. [33] reflected the high susceptibility rates $(74.3 \%-100 \%)$ of NF against different UTI-inducing bacteria and stated that $99.2 \%$ of $E$. coli isolates were NF-susceptible. Similarly, Raeispour et al. [23] implied that $90 \%$ of UTI-inducing E. coli isolates were susceptible to this antibiotic, as well. In another study in Gabon, which was comparable with ours, Mouanga Ndzime et al. [30] identified NF as the most effective drug against UTIinducing E. coli isolates.

Likewise, a high proportion (80.9\%) of E. coli isolates were susceptible to PTZ, confirming the results observed by Critchley et al. [24] in the USA and Halaji et al. [34] in Iran. In this study, AMP and SXT (with resistance rates of $100 \%$ and $80.9 \%$, respectively) were among the less effective antibiotics, a result consistent with those observed in the Gabon [30], USA [24], and Iran [34].

This result for AMP was not far-fetched because in recent years, many Gram-negative bacilli carrying $\beta$-lactamase enzymes have readily become resistant to a wide range of $\beta$-lactam antibiotics. As SXT has always been one of the first-line drugs for the treatment of UTIs, according to the observed evidence, it is recommended to prescribe this drug with regard to the results of antibiotic susceptibility tests.

One notable finding of this study was the relatively high prevalence of MDR (61.7\%) E. coli isolates. Previous studies have reported various MDR frequencies, ranging from

\section{b}

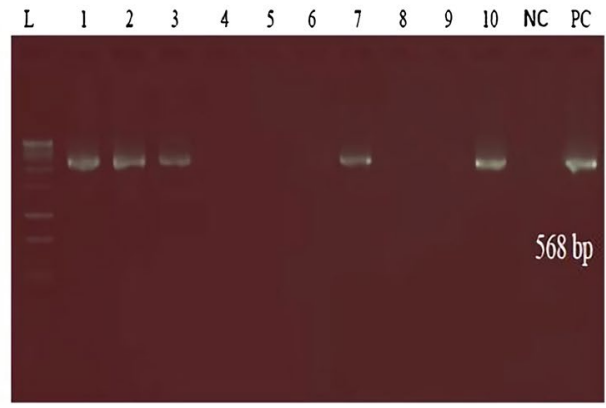

products. From left to right: $\mathrm{L}$ indicates DNA Ladder (100 bp), lanes $1,2,3,7$, and 10 demonstrate $b l a_{\mathrm{IMP}}$-positive (568 bp) E. coli isolates, lane 4, 5, 6, 8, and 9 show $b l a_{\mathrm{IMP}}$-negative $E$. coli isolates, $N C$ indicates negative control, $P C$ indicates positive control of $b l a_{\mathrm{IMP}}$ gene (568 bp) (b)

55.1 to $100 \%$ for UTI-causing $E$. coli isolates [25, 30, 34]. In this study, 7 different antibiotypes were seen in MDR isolates. Previous study from Saudi Arabia showed 70 different antibiotypes in E. coli isolates collected from clinical samples [36]. In another study by Alanazi et al. [37], 7 different antibiotypes were seen in UTI-causing E. coli isolates against ciprofloxacin, ampicillin and co-trimoxazole antibiotics. In this study, according to the results of the antibiogram, the most effective antibiotic against these MDR isolates was the FOS that can be considered for treatment of the MDR UTI-causing $E$. coli. These results necessitate the development of a surveillance program for antibiotic consumption to control the spread of MDR $E$. coli isolates in healthcare systems of our country. In recent years, the outbreak of E. coli sequence type 131 (ST131) isolated from urine culture has become one of the global health problems due to the high prevalence of multidrug resistance. This clone has a wide range of virulence factors including siderophores, adhesins, and toxins which disrupt host defense mechanisms. The majority of these factors are found on mobile genetic elements (MGEs) or pathogenicity islands (PAI), which are capable of being horizontally transmitted among different species [38, 39]. MGEs have a huge impact on bacterial genomes, including causing marked differences in genome size and pathogenicity. Although bacteria have several mechanisms for resisting lateral gene transfer, MGEs play a major role in bacterial evolution and contribute greatly to adaptation to new and changing ecological niches. Most of the resistance genes are acquired by horizontal transfer of plasmids and other MGEs, and this process has been associated with the successful dissemination of particular lineages. Also, MGEs have an important role in virulence gene acquisition and forming new subpopulations among pandemic clones such as E. coli $\mathrm{ST} 131$ [38, 39]. 
This study investigated the production of MBL and AmpC $\beta$-lactamases in UTI-inducing E. coli isolates in HD patients. To the best of our knowledge, this was the first study in this regard in Iran. Today, there are multiple phenotypic methods for detecting $\beta$-lactamases, but owing to the multiplicity of different types of these enzymes, none of the phenotypic methods can identify all types. Therefore, their detection is mostly based on molecular methods such as PCR or real-time PCR [40, 41].

In our survey, AmpC and MBL phenotypes were detected in $29(61.7 \%)$ and 16 (34\%) UTI-causing E. coli isolates, respectively. Similar to these results, Helmy et al. [42] reported a prevalence of $66.6 \%$ for AmpC-producing $E$. coli isolates in Egyptian UTI patients using phenylboronic acid method. A higher prevalence rate $(87.5 \%, \mathrm{n}=175 / 200)$ was also reported for the detection of phenotypic AmpC in UTI-inducing $E$. coli isolates collected from New Zealand by Drinkovic et al. [43]. In opposition to our findings, Jamil et al. [44] stated a lower frequency $(16 \%, \mathrm{n}=12 / 75)$ of UTIcausing E. coli isolates harboring MBLs in Pakistan using phenotypic method. Variations in the results seem to arise from differences in the phenotypic test methods, quality of materials used, and dissimilarity in geographical area.

The results of PCR assay revealed a frequency of $20.7 \%$, $37.9 \%$, and $72.4 \%$ for $b l a_{\mathrm{DHA}-1}, b l a_{\mathrm{ACC}}$, and $b l a_{\mathrm{CMY}-2} \mathrm{AmpC}$ $\beta$-lactamases-producing isolates, respectively. In conformity with our results, findings by Helmy et al. [42] from Egypt and Drinkovic et al. [43] from New Zealand represented the $b l a_{\mathrm{CMY}-2}(89 \%[\mathrm{n}=90 / 101])$ as the predominant type of AmpC in UTI-inducing E. coli isolates. The extensive dissemination of $b l a_{\mathrm{CMY}-2}$ among E. coli isolates could be linked to unique transposon-like element ISEcpl, which is thought to play a role in the transmission of $b l a_{\mathrm{CMY}^{-2}}$ from the Citrobacter freundii chromosome to other Enterobacteriaceae [42]. In another study conducted in Egypt, the prevalence rate of 50\% was reported for $b l a_{\mathrm{DHA}} \mathrm{AmpC}$ in UTI-causing E. coli, while other AmpC genes were not detected [45]. In a study from Nepal, two AmpC genes $b l a_{\mathrm{CIT}}$ and $b l a_{\mathrm{DHA}}$ were detected in $30.6 \%$ and $31.3 \%$ of clinical E. coli isolates, respectively [46]. Another experiment by Shayan and Bokaeian [47], showed a prevalence of $5.0 \%$ and $0.0 \%$ for $b l a_{\mathrm{CMY}-2}$ and $b l a_{\mathrm{FOX}}$ genes, respectively. They did not investigate the remaining AmpC genes. In a recent study from Iran, no $b l a_{\mathrm{MOX}}$ and $b l a_{\mathrm{ECC}}$ genes were found in uropathogenic $E$. coli isolates, while, $b l a_{\mathrm{CIT}}$, $b l a_{\mathrm{FOX}}, b l a_{\mathrm{DHA}}$, and $b l a_{\mathrm{EBC}}$ were detected in $73.6 \%, 10.5 \%$, $10.5 \%$, and $15.8 \%$ of $E$. coli isolates, respectively [48]. Currently, the clinical microbiology laboratories do not have a reliable method of detecting and confirming AmpC $\beta$-lactamases. For this reason, the molecular characterization of $\beta$-lactamases, in particular the AmpC family, is of crucial importance in in terms of molecular epidemiology and genetic contributing factors [48].
This study revealed the high prevalence rate of MBL genes in 24 carbapenem-resistant isolates, as all of them harbored at least one MBL gene. In the current study, the $b l a_{\mathrm{IMP}}$ (72\%) was the most prevalent MBL gene followed by $b l a_{\mathrm{VIM}}$ (28\%) and $b l a_{\mathrm{NDM}}(4 \%)$. The emergence of MBL-producing UTI-inducing $E$. coli isolates could be considered a serious threat to health communities because this pathogen is resistant to numerous antibiotics. In a study by Naeem et al. [49], the NDM-positive rate was $38.5 \%(\mathrm{n}=10 / 26)$ among $E$. coli strains isolated from urine samples that was higher than the current result. In another study from Sudan [50], the $b l a_{\mathrm{VIM}}$ (16.7\%) was the most prevalent MBL gene in clinical E. coli isolates followed by $b l a_{\mathrm{IMP}}(8.3 \%)$ and $b l a_{\mathrm{NDM}}(2.8 \%)$.There is a paucity of data regarding the $b l a_{\mathrm{VIM}}$ and $b l a_{\mathrm{IMP}}$ harboring UTI-causing $E$. coli in Iran. In a recent study from southwest Iran, each of $b l a_{\mathrm{IMP}-1}$ and $b l a_{\mathrm{IMP}-2}$ genes were detected in $8.3 \%$ of uropathogeneic $E$. coli isolates, while the $b l a_{\mathrm{NDM}}$ was detected in $75.0 \%$ of isolates. Also, the $b l a_{\mathrm{VIM}-1}$ and $b l a_{\mathrm{VIM}-2}$ were not detected [51]. In another study by Deldar Abad Paskeh et al. [52] from Iran, a lower occurrence rates of $b l a_{\mathrm{IMP}}(8.7 \%)$ and $b l a_{\mathrm{VIM}}(9.8 \%)$ genes were reported in UTI-causing E. coli compared to the current study. In a recent study from Taiwan, an increasing rate of NDM-positive $E$. coli isolates has been reported in clinical samples. They reported a prevalence rates of $39.1 \%, 30.4 \%, 21.7 \%$, and $8.7 \%$ for NDM, IMP-8, KPC-2, and VIM-1, respectively [53]. NDM is a member of the amber class B $\beta$-lactamases, which can hydrolyze virtually all $\beta$-lactams except monobactam [53]. In China and its neighboring countries, IncX3 plasmids are the most common types of plasmids carrying bla $a_{\mathrm{NDM}}$ in Enterobacteriaceae [54], while in a recent study from Iran, $b l a_{\mathrm{NDM}-1}$ gene was located on both conjugative plasmids: IncFII $\sim 86-\mathrm{kb}$ to $\sim 140-\mathrm{kb}$ and IncA/C [55]. There are various classes of chromosomal and plasmidic MBLs including Sao Paulo metallo- $\beta$-lactamase (SPM), German imipenemase (GIM), and Adelaide imipenemase (AIM) that were not screened in this study and could pave the way for further epidemiological research in the future [56].

The present research showed that $38.3 \%$ of the isolates harbored both MBL and AmpC genes simultaneously. In this regard, co-occurrence of $\beta$-lactamase genes has been reported in several investigations [45, 57], which was in harmony with the results of this study. In recent years, the occurrence of different $\beta$-lactamases in various Gram-negative bacteria has been reported in various studies [58-61]. Due to the financial and traffic constraints caused by the COVID-19 virus pandemic, the current study has the following limitations: the lack of MBLs and AmpC genes sequencing, the lack of antibiogram results for some newer and reserved antibiotics including ceftazidime/avibactam, imipenem/relebactam, ceftolozane/tazobactam, colistin, and tigecycline, and lack of evaluation of other bacteria contributed to UTI in HD patients. Also, due to the non-shareable 
privacy of those patients referred to Army hospitals, we did not have any clinical data of individuals to evaluate the correlation of infections by MDR $E$. coli in HD patients with other important predisposing conditions to detect if any significant trends exist in the prevalence of such MDR strains among different susceptible groups.

\section{Conclusion}

This survey portrayed the high resistance rates of UTIcausing E. coli isolates harboring AmpC and MBLs in HD patients against AMP, SXT, and TGCs. In light of this information, it is recommended to choose treatments based on the antibiogram results, in order to hinder the further spread of MDR isolates. Moreover, the higher efficacy of FOS, PTZ and NF against UTI-inducing E. coli isolates, compared to other antibiotics, made them suitable options for empirical therapy. The emergence of MBL and AmpC co-producing $E$. coli isolates calls for an urgent surveillance program for timely diagnosis and screening of these genes in our healthcare systems. In future, such program can be of great help in preventing the spread of antibiotic resistance in our country, Iran. Another suggestion is to evaluate the other infections and their etiological pathogens such as septicemia in HD patients to prepare a suitable epidemiological data bank in this regard in Iran.

Acknowledgements We gratefully acknowledge AJA University of Medical Sciences, Tehran, Iran for supporting this study.

Author contribution AB: Methodology, Writing- Original draft preparation, Writing-Reviewing and Editing, Formal analysis. SK: Conceptualization, Writing-Reviewing and Editing, Formal analysis. $\mathrm{NH}$ : Conceptualization, Data curation, Formal analysis, Supervision, Writing-Reviewing and Editing. MM: Methodology, Data curation, Formal analysis, Supervision. MKY: Formal analysis, Writing-Reviewing and Editing. NJ: Methodology, Writing- Original draft preparation, Writing-Reviewing and Editing, Formal analysis. MS: Writing- Original draft preparation, Writing-Reviewing and Editing, Formal analysis. All authors read and approved the final manuscript.

Funding This work was supported by the Vice-Chancellor of Research Affairs of the AJA University of Medical Sciences, Tehran, Iran.

Data availability All analyzed data within this study can be obtained from the corresponding author on request.

Code availability Not applicable.

\section{Declarations}

Conflict of interest The authors have no conflict of interest.

Consent to participate Before the initiation of the study, written informed consents were provided by all the HD patients who enrolled in this survey.
Consent for publication Not applicable.

Ethical approval This descriptive cross-sectional study was approved by the Ethics Committee of Army University of Medical Sciences, Tehran, Iran (IR.AJAUMS.REC.1400.105) in accordance with the Declaration of Helsinki.

\section{References}

1. Manhal FS, Mohammed AA, Ali KH (2012) Urinary tract infection in hemodialysis patients with renal failure. J Fac Med Baghdad 54:38-41

2. Múnera JM, Quiceno JN (2019) Colonization and risk of infection by multidrug-resistant bacteria in hemodialysis patients: a topic of concern. Infect 23:205-211

3. El Nekidy WS, Soong D, Mooty M, Ghazi IM (2020) Treatment of recurrent urinary tract infections in anuric hemodialysis patient, do we really need antimicrobial urinary concentration? ID Cases 20:e00748

4. Fatima T, Rafiq S, Iqbal A, Husnain S (2020) Prevalence and antibiogram of MDR E. coli strains isolated from UTI patients1-Year retrospective study at Nishtar medical hospital. Multan SN Compr Clin Med 2:423-431

5. Moue A, Aktaruzzaman SA, Ferdous N, Karim MR, Khalil MM, Das AK (2015) Prevalence of urinary tract infection in both outpatient department and in patient department at a medical college setting of Bangladesh. Int J Biosci 7:146-152

6. Ganeswaran D, Sweeney C, Yousif F, Lang S, Goodman C, Nabi G (2014) Population-based linkage of health records to detect urological complications and hospitalisation following transrectal ultrasound-guided biopsies in men suspected of prostate cancer. World J Urol 32:309-315

7. Shatalov A (2015) Prevalence and antibiotic resistance pattern of Escherichia coli and Klebsiella pneumoniae in urine tract infections at the La Paz Medical center, Malabo Equatorial Guinea. Open J Med Microbiol 5:177

8. Linhares I, Raposo T, Rodrigues A, Almeida A (2013) Frequency and antimicrobial resistance patterns of bacteria implicated in community urinary tract infections: a ten-year surveillance study (2000-2009). BMC Infect Dis 13:1-4

9. Rajabnia M, Forghani MS, Hasani S, Bahadoram M, Mohammadi M, Barahman M (2019) Prevalence and antibiotic resistance pattern of extended spectrum beta lactamase producing Escherichia coli isolated from urinary tract infection. J Renal Inj Prev 8:78-81

10. Aghazadeh M, Sari S, Nahaie M, Hashemi SS, Mehri S (2015) Prevalence and antibiotic susceptibility pattern of E. coli isolated from urinary tract infection in patients with renal failure disease and renal transplant recipients. Trop J Pharm Res 14:649-653

11. Tewari R, Mitra SD, Ganaie F et al (2018) Prevalence of extended spectrum $\beta$-lactamase, AmpC $\beta$-lactamase and metallo $\beta$-lactamase mediated resistance in Escherichia coli from diagnostic and tertiary healthcare centers in south Bangalore, India. Int J Res Med Sci 6:1308-1013

12. El-Kazzaz SS, Abou El-khier NT (2015) AmpC and metallo betalactamases producing Gram negative bacteria in patients with hematological malignancy. Afr J Microbiol Res 9:1247-1254

13. Pérez-Pérez FJ, Hanson ND (2002) Detection of plasmid-mediated AmpC $\beta$-lactamase genes in clinical isolates by using multiplex PCR. J Clin Microbiol 40:2153-2162

14. Maji SK, Maity C, Halder SK, Paul T, Kundu PK, Mondal KC (2012) Studies on drug sensitivity and bacterial prevalence of UTI in tribal population of paschim Medinipur, West Bengal, India. Jundishapur J Microbiol 6:42-46 
15. Clinical and Laboratory Standards Institute (2019) Performance standard for antimicrobial susceptibility testing; seventeenth informational supplement. CLSI Document M100_s19. CLSI, Wayne

16. Galani I, Rekatsina PD, Hatzaki D, Plachouras D, Souli M, Giamarellou H (2008) Evaluation of different laboratory tests for the detection of metallo- $\beta$-lactamase production in Enterobacteriaceae. J Antimicrob Chemother 61:548-553

17. Coudron PE, Hanson ND, Climo MW (2003) Occurrence of extended-spectrum and AmpC beta-lactamases in bloodstream isolates of Klebsiella pneumoniae: isolates harbor plasmid-mediated FOX-5 and ACT-1 AmpC beta-lactamases. J Clin Microbiol 41:772-777

18. Koga VL, Maluta RP, da Silveira WD et al (2019) Characterization of CMY-2-type beta-lactamase-producing Escherichia coli isolated from chicken carcasses and human infection in a city of South Brazil. BMC Microbiol 19:174

19. Mahmoud NE, Altayb HN, Gurashi RM (2020) Detection of carbapenem-resistant genes in Escherichia coli isolated from drinking water in Khartoum Sudan. J Environ Public Health 2020:2571293

20. Koshesh M, Mansouri S, Hashemizadeh Z, Kalantar-Neyestanaki D (2017) Identification of extended- spectrum $\beta$-lactamase genes and ampc- $\beta$-lactamase in clinical isolates of Escherichia coli recovered from patients with urinary tract infections in Kerman. Iran. Arch Pediatr Infect Dis 5:e37968

21. El Hussein RA, Al-Ouqaili MT, Majeed YH (2021) Detection of Helicobacter Pylori infection by invasive and non-invasive techniques in patients with gastrointestinal diseases from Iraq: A validation study. PLoS ONE 16:e256393

22. Sadeghi A, Halaji M, Fayyazi A, Havaei SA (2020) Characterization of plasmid-mediated quinolone resistance and serogroup distributions of uropathogenic Escherichia coli among Iranian kidney transplant patients. BioMed Res Int 2020:2850183

23. Oikonomou KG, Alhaddad A (2017) Isolation rate and clinical significance of uropathogens in positive urine cultures of hemodialysis patients. J Glob Infect Dis 9:56-59

24. Critchley IA, Cotroneo N, Pucci MJ, Mendes R (2019) The burden of antimicrobial resistance among urinary tract isolates of Escherichia coli in the United States in 2017. PLoS ONE 14:0220265

25. Raeispour M, Ranjbar R (2018) Antibiotic resistance, virulence factors and genotyping of Uropathogenic Escherichia coli strains. Antimicrob Resist Infect Control 7:1-9

26. Duicu C, Cozea I, Delean D, Aldea AA, Aldea C (2021) Antibiotic resistance patterns of urinary tract pathogens in children from Central Romania. Exp Ther Med 22:1-7

27. Shakib P, Choolandaimy ZB, Rezaie F, Bahmani M, Delfani S (2020) Systematic review and meta-analysis of carbapenem resistance of Acinetobacter baumannii in Iran. Infect Disord Drug Targets 20:611-619

28. Sheu CC, Chang YT, Lin SY, Chen YH, Hsueh PR (2019) Infections caused by carbapenem-resistant Enterobacteriaceae: an update on therapeutic options. Front Microbiol 10:80

29. Seok H, Choi JY, Wi YM, Park DW, Peck KR, Ko KS (2020) Fosfomycin resistance in Escherichia coli isolates from South Korea and in vitro activity of fosfomycin alone and in combination with other antibiotics. Antibiotics 9:112

30. Mouanga Ndzime Y, Onanga R, Kassa Kassa RF et al (2021) Epidemiology of community origin Escherichia coli and Klebsiella pneumoniae uropathogenic strains resistant to antibiotics in Franceville, Gabon. Infect Drug Resist 14:585-594

31. Kushwaha A, Pokharel K, Kadel AR (2021) Antibiotic resistance to Escherichia coli among urine culture-positive patients in a tertiary care hospital in Nepal: A descriptive cross-sectional Study. J Nepal Med Assoc 59:39-41

32. Naziri Z, Derakhshandeh A, Soltani Borchaloee A, Poormaleknia M, Azimzadeh N (2020) Treatment failure in urinary tract infections: a warning witness for virulent multi-drug resistant ESBL- producing Escherichia coli. Infect Drug Resist 13:1839-1850

33. Lee AC, Mullany LC, Koffi AK et al (2020) Urinary tract infections in pregnancy in a rural population of Bangladesh: population-based prevalence, risk factors, etiology, and antibiotic resistance. BMC Pregnancy Childbirth 20:1

34. Halaji M, Shahidi S, Atapour A, Ataei B, Feizi A, Havaei SA (2020) Characterization of extended-spectrum $\beta$-lactamaseproducing uropathogenic Escherichia coli among Iranian kidney transplant patients. Infect Drug resist 13:1429-1437

35. Zhu FH, Rodado MP, Asmar BI, Salimnia H, Thomas R, AbdelHaq N (2019) Risk factors for community acquired urinary tract infections caused by extended spectrum beta-lactamase (ESBL) producing Escherichia coli in children: a case control study. Infect Dis (Lond) 51:802-809

36. Yasir M, Ajlan AM, Shakil S et al (2018) Molecular characterization, antimicrobial resistance and clinico-bioinformatics approaches to address the problem of extended-spectrum $\beta$-lactamase-producing Escherichia coli in western Saudi Arabia. Sci Rep 8:14847

37. Alanazi MQ, Alqahtani FY, Aleanizy FS (2018) An evaluation of $E$. coli in urinary tract infection in emergency department at KAMC in Riyadh, Saudi Arabia: retrospective study. Ann Clin Microbiol Antimicrob 17:3

38. da Cruz Campos AC, Couto N, da Silva Andrade NL et al (2020) Virulence and resistance properties of E. coli isolated from urine samples of hospitalized patients in Rio de Janeiro, Brazil-The role of mobile genetic elements. Int J Med Microbiol 310:151453

39. Pajand O, Rahimi H, Darabi N et al (2021) Arrangements of mobile genetic elements among virotype E subpopulation of Escherichia coli sequence type 131 strains with high antimicrobial resistance and virulence gene Content. Msphere 6:e00550-e621

40. Dehbashi S, Tahmasebi H, Alikhani MY, Keramat F, Arabestani MR (2020) Distribution of Class B and Class A $\beta$-lactamases in clinical strains of Pseudomonas aeruginosa: comparison of phenotypic methods and high-resolution melting analysis (HRMA) assay. Infect Drug Resist 13:2037-2052

41. Sharma M, Singhal L, Gautam V, Ray P (2020) Distribution of carbapenemase genes in clinical isolates of Acinetobacter baumannii and a comparison of MALDI-TOF mass spectrometrybased detection of carbapenemase production with other phenotypic methods. Indian J Med Res 151:585

42. Helmy MM, Wasfi R (2014) Phenotypic and molecular characterization of plasmid mediated AmpC $\beta$-lactamases among Escherichia coli, Klebsiella spp, and Proteus mirabilis isolated from urinary tract infections in Egyptian hospitals. Bio Med Res Int 2014:171548

43. Drinkovic D, Morris AJ, Dyet K, Bakker S, Heffernan H (2015) Plasmid-mediated AmpC beta-lactamase-producing Escherichia coli causing urinary tract infection in the Auckland community likely to be resistant to commonly prescribed antimicrobials. $\mathrm{NZ}$ Med J 128:50-59

44. Jamil J, Haroon M, Sultan A, Khan MA, Gul N (2018) Prevalence, antibiotic sensitivity and phenotypic screening of ESBL/ MBL producer $E$. coli strains isolated from urine; District Swabi. KP Pakistan J Pak Med Assoc 68:1704-1707

45. Mohamed ES, Khairy RM, Abdelrahim SS (2020) Prevalence and molecular characteristics of ESBL and AmpC $\beta$-lactamase producing Enterobacteriaceae strains isolated from UTIs in Egypt. Antimicrob Resist Infect Control 9:1-9

46. Aryal SC, Upreti MK, Sah AK et al (2020) Plasmid-mediated AmpC $\beta$-lactamase CITM and DHAM genes among gram-negative clinical isolates. Infect Drug Resist 13:4249-4261 
47. Shayan S, Bokaeian M (2015) Detection of ESBL- and AmpCproducing $E$. coli isolates from urinary tract infections. Adv Biomed Res 4:220

48. Dolatyar Dehkharghani A, Haghighat S, Rahnamaye Farzami M, Rahbar M, Douraghi M (2021) Clonal relationship and resistance profiles among ESBL-producing Escherichia coli. Front Cell Infect Microbiol 11:499

49. Naeem S, Bilal H, Muhammad H et al (2021) Detection of $b l a_{\mathrm{NDM}-1}$ gene in ESBL producing Escherichia coli and Klebsiella pneumoniae isolated from urine samples. J Infect Dev Ctries 15:516-522

50. Adam MA, Elhag WI (2018) Prevalence of metallo- $\beta$-lactamase acquired genes among carbapenems susceptible and resistant Gram-negative clinical isolates using multiplex PCR, Khartoum hospitals, Khartoum Sudan. BMC Infect Dis 18:1-6

51. Matin FZ, Rezatofighi SE, Ardakani MR, Akhoond MR, Mahmoodi F (2021) Virulence characterization and clonal analysis of uropathogenic Escherichia coli metallo-beta-lactamaseproducing isolates. Ann Clin Microbiol Antimicrob 20:50

52. Deldar Abad Paskeh M, Mehdipour Moghaddam MJ, Salehi Z (2020) Prevalence of plasmid-encoded carbapenemases in multidrug resistant Escherichia coli from patients with urinary tract infection in northern Iran. Iran J Basic Med Sci 23:586-593

53. Huang YS, Tsai WC, Li JJ et al (2021) Increasing New Delhi metallo- $\beta$-lactamase-positive Escherichia coli among carbapenem non-susceptible Enterobacteriaceae in Taiwan during 2016 to 2018. Sci Rep 1:2609

54. Wu W, Feng Y, Tang G et al (2019) NDM metallo- $\beta$-lactamases and their bacterial producers in health care settings. Clin Microbiol Rev 32:e0115-118

55. Solgi H, Nematzadeh S, Giske CG et al (2020) Molecular epidemiology of OXA-48 and NDM-1 producing enterobacterales species at a University Hospital in Tehran, Iran, between 2015 and 2016. Front Microbiol 11:936
56. Boyd SE, Livermore DM, Hooper DC, Hope WW (2020) Metallo- $\beta$-lactamases: structure, function, epidemiology, treatment options, and the development pipeline. Antimicrob Agents Chemother 64:e00397-e420

57. Ugwu MC, Shariff M, Nnajide CM et al (2020) Phenotypic and molecular characterization of $\beta$-lactamases among enterobacterial uropathogens in Southeastern Nigeria. Can J Infect Dis Med Microbiol 2020:843904

58. Al-Ouqaili MT, Khalaf EA, Al-Kubaisy SH (2020) DNA sequence analysis of $b l a_{\mathrm{VEB}}$ gene encoding multi-drug resistant and extended-spectrum $\beta$-lactamases producer isolates of Enterobacteriaceae and Pseudomonas aeruginosa. Open Microbiol J $14: 40-47$

59. Al-Kubaisy SH, Hussein RA, Al-Ouqaili MT (2020) Molecular Screening of Ambler class $C$ and extended-spectrum $\beta$-lactamases in multi-drug resistant Pseudomonas aeruginosa and selected species of Enterobacteriaceae. Int J Pharm Res 12:3605-3613

60. Khalaf EA, Al-Ouqaili MT (2019) Molecular detection and sequencing of $S H V$ gene encoding for extended-spectrum $\beta$-lactamases produced by multidrug resistance some of the Gramnegative bacteria. Int J Green Pharm 12:S910-S918

61. Al-Ouqaili MT, Jaloot AS, Badawi AS (2018) Identification of an OprD and $b l a_{\mathrm{IMP}}$ gene-mediated carbapenem resistance in Acinetobacter baumannii and Pseudomonas aeruginosa among patients with wound infections in Iraq. Asian J Pharm 12:S959-S965

Publisher's Note Springer Nature remains neutral with regard to jurisdictional claims in published maps and institutional affiliations. 